\title{
Features of Application of Classroom Response System at the Lectures in Russia and Israel
}

\author{
Boris E. Starichenko ${ }^{1}$, Artem N. Egorov ${ }^{1} \&$ Roman Yavich $^{2}$ \\ ${ }^{1}$ Ural State Pedagogical University, Yekaterinburg, Russia \\ ${ }^{2}$ Ariel University, Ariel, Israel \\ Correspondence: Roman Yavich, Ariel University, Ariel, Israel. E-mail: romany@ariel.ac.il
}

Received: May 19, 2013

Accepted: June 14, 2013

Online Published: June 17, 2013

doi:10.5430/ijhe.v2n3p23

URL: http://dx.doi.org/10.5430/ijhe.v2n3p23

\begin{abstract}
The article is devoted to the study of teaching opportunities of classroom response sys-tems (CRS) and the conditions for their effective use in the teaching process. In the course of research more than 260 students of Ural State Pedagogical University (Russia, Yekaterinburg) and Ariel University Center of Samaria (Israel, Ariel) were surveyed to reveal their attitude to basic CRS abilities. According to the survey, students of both countries highly appreciate motivation, activating and management functions of CRS. The conditions for effective CRS application by teacher are studied based on experimentally received data.
\end{abstract}

Keywords: Teacher feedback, Classroom response systems, Management training, Modern lecture

\section{Research Problem}

The correct use of information and communication technologies (ICT) in education can solve two important didactic tasks: individualization of training and activation of learning activities of students. The necessity and importance of these challenges has been declared long ago, however, there were no real opportunities of their solution within the traditional scheme of organization of educational process (without the use of ICT). The main reason, as the research of B.E. Starichenko (1998) shows, is the impossibility on the part of one teacher to organize information exchange with many students, which by volume and speed is required for active learning activities. Digital libraries, currently used by universities, distance learning systems, web-training courses, computer control systems, provide the student with efficient access to diverse and large information resources, allow building a personalized learning path. The availability and accessibility of such developed resources, is a condition for enhancing learning activities, improving cognitive independence, shift of emphasis in the construction of the educational process to independent work of students.

As another condition that promotes learning activities is the feedback between the students and the teacher, which corresponds to the general theory of system control. In the works of many authors (R.F. Abdeev, V.P. Bespalko, A.A. Bratko, D.I. Dubrovsky, E.I. Mashbits, B.E. Starichenko, etc.), who reviewed the informational aspects of the learning process, a high didactic value of feedback between the students and the teacher is noted. On the basis of information received through the feedback channel, the teacher has the opportunity to control the course of the receiving and learning educational information (Starichenko, 1998).

The theory of feedback in the educational process is rooted in the works of E.L. Thorndike, 1911. It deals with the issues of building models of feedback in the educational process, and discusses effective tools and methods for its implementation (Fies \& Marshall, 2006).

The control theory for the general case defines the requirements to information received via the feedback channels: completeness, correctness, timeliness. The currently used ICT tools can ensure fulfillment of all the above conditions. As the works of B.E. Starichenko, N. Davidovitch, R. Yavich reveal, proper organization of information education resources and the use of modern communication tools (first of all, network) enable not only to improve provision of information and management of educational process in the framework of traditional forms of organization for high school teaching, but also gives rise to fundamentally new forms: remote lectures, seminar-forums, distance consultations, forums of disciplines, means of remote control and self-control, the creation and use of wiki-resources. The application of the listed means built on a systematic basis helps to significantly alter the content and organization of the classroom practical training sessions (lab work, seminars, practices, controls) and, especially, self-learning 
activities.

However, it should be noted that pedagogical and methodological problems associated with the use of ICT in the classroom lecture sessions remain outstanding to date. As a rule, the use of modern technologies at the lectures is reduced to computer presentations. There are many works in which requirements for such presentations are substantiated and recommendations for their use are formulated. If the lecturer is actively using such presentations, and a comprehensive summary of the lectures (or manual) is available to the student online at the site of the discipline, then there is no need of abstracting material, which, on the one hand, releases training time, and on the other hand, leads to the necessity of application of active forms of interaction of the lecturer with the audience. The latter, as stated above, is impossible without provision of feedback of the lecturer with the audience. Of course, in small audience (20-30 people) the lecture can be conducted in the form of discussion, in which a skilled lecturer will be able to involve everyone. In a large audience (50-300 people) such form is not acceptable, as the lecturer loses the ability to track the activity of each listener.

The presence of feedback from the audience allows the instructor during the lecture to identify and assess mastering of the material by the students and adjust the presentation, if necessary. Usually the lecturer establishes such connection through the questions addressed to the audience: "Is it clear?", "Any questions?" etc. However, a verbal examination of the audience, when the students must give answers in public, as a rule, does not reflect a true understanding and mastery of the material, due to the psychological characteristics of individual behavior in a large group of students.

In this connection it is relevant to study the possibilities of using technical means at the lectures which could provide a teacher with a prompt feedback from a large audience in real-time. The problem involves many aspects: technological (what technical means are necessary?), substantive (what are the features of presentation of the material?), organizational (how to organize the activities of the audience?), analytical (what should be the content of the information in the feedback loop, and what conclusions can the teacher make in the course of the lecture?) apparently, this list can be continued. Any of these aspects of the problem can be adopted as the primary (original) -it will determine the resolution of the rest.

In our study as a starting point, we have taken technical and technological possibilities of classroom response systems (CRS). Such systems are actively used in educational institutions in the USA (Crouch \& Mazur, 2001, Fies, \& Marshall, 2006, Mory, 2003), but there is little experience of their use in high schools of Russia and Israel. It can be expected that the solution of the above problems will fundamentally change the technology of conduct of lectures to make it adequate to the requirements of modern education.

The present work performed in the Ural State Pedagogical University (Russia, Ekaterinburg) and the Ariel University Center of Samaria (Israel, the city of Ariel), is the development of collaborative research on various aspects of the application of information technologies in the educational process of high school (Yavich, Starichenko, Makhrova \& Davidovich, 2007, Starichenko B.E., Starichenko E.B., Egorov, Davidovich \& Yavich, 2010). A number of teaching and organizational aspects of the application of CRS, the results of practical use of CRS at the lecture classes in Russia, as well as some aspects of the design of lectures with the use of CRS have been described in our previous studies (Starichenko \& Egorov, 2011a, 2011b, 2012, Starichenko, Egorov, Davidovitch \& Yavich, 2012). Continuing this study, we tried to examine the attitudes of students of Russia and Israel to the use of classroom response systems in the classroom and to identify how the scores of students of different countries are correlated and how scores of students are in line with our expectations.

\section{Organization of research and its results}

Classroom response systems are regularly used at the lectures on various disciplines (philosophy, pedagogy, psychology, etc.) with students from different faculties (human and technical) of Ural State Pedagogical University and the Ariel University Center of Samaria during the 2011-12 school year.

We assume (these expectations can be considered as a scientific hypothesis, which were tested in this study), that regular and consistent application of CRS when reading lectures will provide with:

- increase of the cognitive activity of students in class;

- changes in the content of lectures (in particular, the nonlinear nature of its construction);

- expanding the opportunity of the teachers to manage the course of lectures;

For the organization of the discussions and identification of the audience opinion by CRS the problematic issues were included in the lecture. At the end of the lecture the questions were used which allow to verify the learning of 
received material. There were also used some specific for disciplines forms of tasks, for instance, philosophical problems (discipline "Philosophy") and interactive psychological experiments (discipline "Psychology").

Empirically, it was established that the optimal time interval between two «CRS» (problem) issues is 15-20 minutes (ie 4-6 questions per lecture), however, there were examples of more frequent use of CRS, if it was required by the content of the lecture.

After the end of the lecture courses in order to identify students' attitudes to the use of CRS a questionnaire poll was conducted in which 142 students of the Ural State Pedagogical University and 120 students of the University Center of Samaria took part. Processing the questionnaire results consisted in averaging numbers of sample estimation or in defining the percentage of those who have selected this or that variant of answer.

Questioning yielded the following results:

Table 1. The results of questioning of the student

\begin{tabular}{lll}
\hline The text of the question and the answer options & Russia & Israel \\
\hline 1. Do you think it is justified and beneficial to use CRS at the lectures? & & \\
Yes, no doubt & $76 \%$ & $79 \%$ \\
Yes, mainly in the humanities & $20 \%$ & $7 \%$ \\
Yes, mainly in natural sciences & $2 \%$ & $8 \%$ \\
No, it is not necessary at all & $2 \%$ & $6 \%$
\end{tabular}

2. To what extent is the use of CRS by the teacher helps to activate your work in class?

$\begin{array}{lll}\text { Yes, significantly } & 55 \% & 53 \% \\ \text { Yes, in the discussion of certain problematic issues } & 43 \% & 18 \% \\ \text { Does not contribute to the activization } & 2 \% & 29 \%\end{array}$

3. Is it interesting and important for you to see the opinions of other students on the issues discussed?

Yes, it is always interesting

$\begin{array}{ll}41 \% & 85 \% \\ 56 \% & 9 \% \\ 3 \% & 6 \%\end{array}$

4. Is it important for you to immediately get the evaluation of your answer?

Yes, it is very important

$68 \% \quad 74 \%$

Yes, if the answer turns out to be true

$21 \% \quad 18 \%$

No, I am distressed by my wrong answers

$6 \% \quad 5 \%$

I am indifferent for the evaluation, if it is not taken into account in

$5 \%$

$3 \%$

the performance journal

5. How do you think, can the result of a general poll to influence the further construction of the lecture by the teacher?

Yes, it should

$\begin{array}{ll}42 \% & 81 \% \\ 51 \% & 12 \% \\ 5 \% & 5 \% \\ 2 \% & 2 \%\end{array}$

\section{Discussion of the research results}

Yes, in case of questions with ambiguous answers

This is undesirable because deviation from the lecture plan occurs. $\quad 5 \%$

The lecture plan should not be deviated from - the poll should not $2 \%$ influence the course of the lecture

In our previous works the groups of basic didactic possibilities of CRS were distinguished: motivational, activating and management (Starichenko et al., 2010, 2011). Correlation of the results of the survey (shown in Table 1) with these groups allows us to construct the following conclusions. 
1. The degree of acceptance and approval of the CRS technology by the students in both countries is very high. The majority considers their application reasonable and appropriate, offer to apply it to other educational disciplines as well. The focus of the Ural students to the humanities may be associated mainly with a predominantly humanitarian nature of pedagogical education they receive. We had the following positive feedback from students about the CRS lectures. "I wish that this method of learning was used as often as possible and on different subjects." "CRS is very helpful in class." "This type of work is convenient and visual. I loved it." "It should be applied at every lecture!!!".

2. The group of activating functions (Starichenko et al., 2010, 2011) includes:

- Ensuring the involvement of each participant in the course of the presentation;

- Activization of learning activities of students;

- Development of analytical thinking;

- Building of skills for scientific discussion.

This group received strong positive support by Russian students: $98 \%$ of respondents noted an increase in the involvement of the course of CRS lectures, while almost one-third of Israeli students believe that the use of CRS is not conducive to enhancing their learning activities. This phenomenon in our view can be explained by the different age groups of respondents: 17-19 years in Russia and 21-25 years in Israel - young people start education in higher educational institutions in Israel after they finish military service at the age of 20-21 (Yavich, 2008). The use of CRS at a lecture creates external motivation for learning and increased educational activity takes place by external pedagogical influences of a teacher, which is habitual and is perceived as normal state of things by the students who had just graduated from high school, but can be quite unacceptable for adults, past an army training. However, support for the group of activating functions by the students is high in both countries - here is the didactic effect of CRS, which is fully consistent with our initial expectations.

3. The group of motivational functions, according to (Starichenko et al., 2010, 2011), included:

- monitoring of presence in the auditorium;

- creating of an interactive and engaging atmosphere in the classroom;

- anonymous survey;

- checking the understanding and assimilation of new material by the listeners.

Teachers and students of both countries emphasized the creative, exciting atmosphere in the classroom during lectures using CRS. Howewer, the application of CRS did not influence much the attendance of lectures by Russian students - from our point of view, this circumstance is not related with CRS itself, but with organizational learning conditions (in particular, the fact that in many Russian high schools attendance at training sessions is not mandatory even for full-time training students, and does not bind directly to the final indicators of education). It is interesting to note that the Israel students stressed the importance of the anonymous nature of the survey, while the Ural students did not attach much importance to this characteristic.

4. In the group of management features, the following stood out:

- operational feedback from the audience, regardless of its size;

- parallel collection of survey results of all students;

- instantaneous processing and output of the survey results in a convenient form for further analysis;

- the ability to view and analyze individual responses, identification of group patterns;

- accumulation, storage and further processing of individual and group results of the survey.

The statement that CRS greatly expand the opportunities of the teacher to manage the course of lectures, received brilliant confirmation in practice. The vast majority of students from both countries noted the importance of prompt evaluation of their work, thus confirming the urgent need to implement immediate feedback of the student, including lectures and classes. This group of options is crucial: the students can be activated and motivated without CRS, but it is impossible to fully control the course of the lecture.

Most of the respondents are aware that the use of CRS requires from the teachers new approaches to the construction of the lecture. In particular, its presentation ceases to be linear since it depends on the nature of the responses to the problematic issues with mixed solutions chosen by most students - the further course of the presentation can vary. This, in turn, imposes higher requirements for substantive and scientific outlook of the teacher and his ability to 
navigate in the learning situation and take appropriate pedagogical decisions. The lecturer is no longer a simple translator of texts according to a predefined plan! Preparing good problem issues that can be considered "branch points" in the lecture is not an easy task, requiring a mastery of the training material by the teacher on the one hand, and the prediction of a possible response to these questions by the student audience, on the other hand. Difficulties associated with the accentuation of the situations in which the use of the problematic issue is appropriate, as well as directly to the wording of questions is noted by all teachers. Correction of problematic issues after their approbation at the lecture appears to be important as well.

\section{Conclusion}

Modern lecture should be technology intensive, ensuring maximum efficiency of transmission and assimilation of educational information. The conducted study, whose results are presented in this paper show that the main and most expected pedagogical effects of using CRS are actually realized, the use of CRS allows to transfer to the active teaching methods in class. The use of CRS is approved by students and teachers of different national mentality, where we can find the community of didactic value of CRS for the various national systems of higher education. This result is important from the point of view of bringing the Russian higher education system to the international standards.

\section{References}

Crouch, C.H., Mazur, E. (2001). Peer Instruction: Ten years of experience and results. Am. J. Phys., 69 (9), 970-977. http://dx.doi.org/10.1119/1.1374249

Davidovich, N., Yavich, R.P., Domoshnitsky, A. (2012). Mathematical Games: International Mathematics Olympiad for Students. Far East Journal of Mathematical Education, 9(2), 133-140.

Domoshnitsky, A., Yavich, R.P. (2009). Mathematical Competitions for University Students. Proceedings of the 10th International Conference Models in Developing Mathematics Education (pp. 143-145). Dresden, Saxony, Germany.

Domoshnitsky, Alexander, and Roman Yavich. (2009) . Intemet Mathematical Olympiads. HTW Dresden, 2009.

Domoshnitsky, A., Yavich, R., Bugaenko, V., Kannel-Belov, A. (2012). International Mathematical Internet Olympiad. Journal of Systemics, Cybernetics and Informatics, 10(5), 50-54.

Fies, C., Marshall, J. (2006). Classroom Response Systems: A Review of the Literature. Journal of Science Education and Technology, 15(1), 101-109. http://dx.doi.org/10.1007/s10956-006-0360-1

Mory, E.H. (2003). Feedback Research Revisited. Handbook of research for educational communications and technology, 2-nd Edition (pp. 745-783). Mahwah, NJ, Lawrence Erlbaum.

Starichenko, B.E. (1998). Computer technologies in the optimization of the educational systems. Yekaterinburg,: USPU.

Starichenko, B.E., Egorov, A.N. (2011a). Russian High School 'Clickers' Experience. In-tercultural ties in higher education and academic teaching (pp.154-165). Ariel University Center of Samaria, Israel.

Starichenko, B.E., Egorov, A.N. (2011b). Theory and practice of using classroom feedback system in the work of university teachers. Pedagogical Education in Russia, 4, 135-146.

Starichenko, B.E., Egorov, A.N. (2012). Activation of learning activities of students in a lecture using classroom feedback system. The world of science, culture and education, 2 (33), 149-152.

Starichenko, B.E., Starichenko, E.B., Egorov, A.N. Davidovich, N., Yavich, R.P. (2010). Classroom systems of survey in the lecture work of a teacher. Innovative technologies in the educational process of higher education: Proceedings of the VII International Scientific Conference (part 1, pp. 77-82). Ural. State. ped. Univ, Ekaterinburg.

Starichenko, B.E, Egorov A.N, Davidovitch, N., Yavich R.P. (2012). Classroom survey systems in teacher lecturing. Innovative Technologies in Higher Education. Ekaterinburg.

Yavich, R.P. (2008). Management of mathe-matical training of students of technical high school on the basis of telecommunications technology. Dis. candidate. ped. science. Ekaterinburg.

Yavich, R.P. (2013). Social networks and students. Research Journal of Management Sciences, 2(2), 1-3.

Yavich, R.P., Starichenko, B.E., Makhrova, L.V., Davidovich, N. (2007). Management of educational activity of students on the basis of network information technology. Education and Science: Math, 6, 3-15. 